\title{
Spica Prunellae extract suppresses the growth of human colon carcinoma cells by targeting multiple oncogenes via activating miR-34a
}

\author{
YI FANG，LING ZHANG，JIANYU FENG，WEI LIN，QIAOYAN CAI and JUN PENG
}

Academy of Integrative Medicine and Fujian Key Laboratory of Integrative Medicine on Geriatrics, Fujian University of Traditional Chinese Medicine, Fuzhou, Fujian 350108, P.R. China

Received January 19, 2017; Accepted June 19, 2017

DOI: 10.3892/or.2017.5792

\begin{abstract}
Spica Prunellae is the spike of the herb Prunella vulgaris L. in traditional Chinese medicine which is often used for the treatment of various cancers including colorectal cancer. In the present study, we found that a key tumor suppressor, microRNA-34a (miR-34a) is involved in the antitumor activity for Spica Prunellae. Human colon carcinoma HCT-8 cells treated with an ethanol extract of Spica Prunellae (EESP) had significantly decreased cell proliferation and viability, in a dose-dependent manner. Flow cytometry analysis with Annexin V/PI staining analysis revealed that EESP treatment could induce apoptosis of HCT-8 cells. The level of miR-34a was upregulated in HCT-8 cells following EESP treatment, whereas expression levels of its target genes Notch1, Notch2 and $\mathrm{Bcl}-2$ were downregulated. Inhibition of miR-34a rescued the expression of these target genes. These results revealed that Spica Prunellae can suppress the growth of HCT- 8 cells by targeting Notch1, Notch2 and Bcl-2 via activation of miR-34a.
\end{abstract}

\section{Introduction}

Colorectal cancer (CRC) is characterized by the formation of malignant tumors in the colon or rectum. Recently, there have been a notable decrease in the incidence rates of CRC, which can be largely attributed to improvements in screening techniques, allowing early detection and removal of precancerous polyps (1). Nevertheless, morbidity and mortality for CRC is still the 5th most malignant tumor in China (2) and the 3rd of cancer-related deaths in the USA (1). Clinical treatment of CRC usually involves surgery, chemotherapy, radiation therapy

Correspondence to: Dr Jun Peng, Academy of Integrative Medicine and Fujian Key Laboratory of Integrative Medicine on Geriatrics, Fujian University of Traditional Chinese Medicine, Fuzhou, Fujian 350108, P.R. China

E-mail: pjunlab@hotmail.com

Key words: Spica Prunellae, miR-34a, colorectal cancer, Notch pathway, herbal medicine and palliative care, depending on the patient status and tumor characteristics (3). Such treatments are often painful and expensive, and are associated with a high risk of postoperative recurrence and tumor metastasis. Therefore, there is urgent need to discover safer, cheaper and more effective methods of treatment for colorectal cancer.

In Western herbal medicine, Prunella vulgaris L. is a well known herb for self healing. Similarly, in traditional Chinese medicine (TCM), the spike of Prunella vulgaris L. termed Spica Prunellae, is often used for the prevention and remedy of various illnesses (4). The chemical components of Spica Prunellae contain various bioactive compounds including triterpenes, flavonoids, phenolic compounds and carbohydrates (5-8). Among these, oleanolic acid is associated with anticancer (9-11) and anti-inflammatory (12) properties, ursolic acid has shown anti-allergic and anti-inflammatory activities $(11,13)$, rosmarinic acid has demonstrated antioxidant $(14,15)$, neuroprotective $(16,17)$ and anti-inflammatory effects (18), and polysaccharide has anticancer activity (19). As a whole, Spica Prunellae has also been reported to exhibit immunosuppressive activity (20), anti-angiogenic activity (21), vascular inflammation properties (22), anti-estrogenic activity (23), anti-HIV activity $(24,25)$, and anticancer activity $(19,26)$. With regards to the anticancer activity of Spica Prunellae, research has demonstrated that it can promote cell apoptosis $(9,27,28)$, regulate the cell cycle $(28,29)$, as well as suppress cell invasion and migration (26). Furthermore, this anticancer activity was mediated by a variety of genes, including Bcl-2, Bax, Bad, c-Jun N-terminal kinases (JNK), caspase-3 and signal transducer and activator of transcription 3 (STAT3) $(9,26,30)$.

miRNAs are a cluster of small non-coding RNA molecules containing 20-25 nucleotides, which play crucial roles during transcription and post-transcriptional regulation of gene expression (31). miRNAs can suppress tumor growth, progression and metastasis by regulating and stabilizing the metastatic nature of cancers (32). miR-34a is a tumor suppressor of the miR-34 family, which can regulate Bcl-2, Notch1 and Notch2 expression to promote apoptosis of cancer cells (33-35). Since Bcl-2 is also mediated by Spica Prunellae $(9,30)$, we hypothesized that miR-34a must take part in the antitumor activity for Spica Prunellae. 
We previously demonstrated that Spica Prunellae suppressed cell proliferation with G1/S cell cycle arrest and promoted mitochondrion-dependent apoptosis in HT-29 colon cancer cells $(27,29)$. Moreover, it inhibited tumor angiogenesis in vitro and in vivo $(21,26)$. Our present study reveals that EESP can suppress the growth of HCT-8 colon carcinoma cells and promote cell apoptosis. We propose a likely mechanism of EESP function, via the activation of miR-34a pathway and its regulation of Notch1, Notch2 and Bcl-2 expression. These findings provide important insight into understanding the role of miR-34a in regulating the antitumor activity for Spica Prunellae, and establish a theoretical basis for the prevention and clinical treatment of CRC.

\section{Materials and methods}

Preparation of EESP. Prunella vulgaris L. plants were purchased from Guo Yi Tang Chinese Herbal Medicine store (Fujian, China). The herb was collected from Hunan Province in China. The extraction and the chemical profile of EESP were prepared by Lin et al (26). EESP powder was then dissolved with DMSO to a stock concentration of $500 \mathrm{mg} / \mathrm{ml}$. The final concentration of DMSO in working solution for all experiments was $\leq 0.4 \%$.

Cell culture. Human carcinoma HCT-8 cells were obtained from Nanjing Kaiji Biological Technology Development Co., Ltd. (Nanjing, China). RPMI-1640 medium, fetal bovine serum (FBS), trypsin-EDTA and penicillin-streptomycin were obtained from Hyclone (Carlsbad, CA, USA). The cells were cultured in RPMI-1640 medium supplemented with 10\% FBS, $100 \mathrm{U} / \mathrm{ml}$ penicillin and $100 \mu \mathrm{g} / \mathrm{ml}$ streptomycin (Hyclone), in a $37^{\circ} \mathrm{C}$ humidified incubator with $5 \% \mathrm{CO}_{2}$.

Cell viability evaluation and $\mathrm{IC}_{50}$ determinations. HCT- 8 cells were seeded with a density of $0.5 \times 10^{4}$ cells $/ \mathrm{ml}$ in 96 -well plates. Cell culture medium was replaced with different concentrations $(0,0.25,0.50,0.75,1.00,1.25$ and $1.50 \mathrm{mg} / \mathrm{ml})$ of EESP for $48 \mathrm{~h}$ at $80-90 \%$ cell confluency. Cell viability was determined at $570 \mathrm{~nm}$ using 3-(4,5-dimethylthiazol-2-yl)-2, 5-diphenyltetrazolium bromide (MTT) colorimetric assay with ELX800 (BioTek, Winooski, VT, USA). Subsequent cell survival rates and $\mathrm{IC}_{50}$ of EESP were calculated and analyzed using SPSS 16.0 software.

Colony formation. HCT- 8 cells were seeded with a density of $2 \times 10^{5}$ cells $/ \mathrm{ml}$ into 6 -well plates. After treatment with different concentrations $(0,0.25,0.50,0.75$ and $1.00 \mathrm{mg} / \mathrm{ml})$ of EESP for $48 \mathrm{~h}$, cells were collected and reseeded with a density of $1 \times 10^{3}$ cells/well in new 6 -well plates. Cells were maintained in RPMI-1640 medium supplemented with $10 \%$ FBS, penicillin and streptomycin for 2 weeks. The resulting cell colonies were fixed using methanol, stained with $0.01 \%$ crystal violet and counted.

Apoptosis detection by flow cytometry analysis with Annexin V/PI staining. After treated with different concentrations $(0,0.25,0.50$ and $1.00 \mathrm{mg} / \mathrm{ml})$ of EESP for 48 h, HCT-8 cells were operated with Annexin V FITC/ PI Apoptosis Detection kit from Nanjing Kaiji Biological
Technology Development Co., Ltd. Finally, cell apoptosis was detected by fluorescence-activated cell sorting (FACS) (Becton-Dickinson, San Jose, CA, USA).

Transfection. HCT- 8 cells were seeded with a density of $2 \times 10^{5}$ cells $/ \mathrm{ml}$ in 6 -well plates and transfected with miR-34a inhibitor (RiboBio Co. Ltd., Guangzhou, China) or negative control with Lipofectamine 2000 (Life Technologies Corp., Shanghai, China) according to the manufacturer's instructions when cells are at 50-60\% confluency. Transfections were performed in triplicate independent experiments. After $24 \mathrm{~h}$, culture medium was replaced by the $\mathrm{IC}_{50}$ volume of EESP for $48 \mathrm{~h}$.

RNA preparation. Total RNA of cells was extracted using TRIzol reagent (Life Technologies, Grand Island, NY, USA) according to the manufacturer's instructions. Nanodrop spectrophotometer (Nanodrop Technologies, Oxfordshire, UK) was used to assessed the quantity and quality of RNA.

$R T$ - $q P C R$. cDNA synthesis was carried out following the instruction of PrimeScript ${ }^{\mathrm{TM}}$ RT reagent kit with gDNA Eraser: Perfect Real-time (Takara, Dalian, China). The RT-primers of miR-34a were designed based on Chen et al (36). Primers for U6 was designed by Primer Premier 5.0 (37), primers for miR-34a was provided by Yang et al (38) and other primers were obtained from RTPrimerDB or Primer Bank (data not shown). qPCR was performed using DyNAmo ColorFlash SYBR Green qPCR kit (Thermo Fisher Scientific Inc., Waltham, MA, USA) and Applied Biosystems ${ }^{\circledR} 7500$ Real-time PCR System (Life Technologies).

Western blotting. Proteins were extracted by RIPA buffer (Thermo Fisher Scientific Inc.) and separated in $7.5 \%$ SDS-PAGE and then transferred to NC membranes (Millipore, Billerica, MA, USA) by semi-dry electrotransfer. After incubation with antibody against Notch1, Notch2 [AI Bo (Shanghai) Trading Co., Ltd., Shanghai, China], Bcl-2 and GAPDH (Thermo Fisher Scientific Inc.) and anti-rabbit IgG, HRP-linked antibody (Cell Signaling Technology, Inc., Danvers, MA, USA), the bands were detected with SuperSignal ${ }^{\mathrm{TM}}$ West Pico Chemiluminescent Substrate or SuperSignal ${ }^{\mathrm{TM}}$ West Femto Maximum Sensitivity Substrate (Thermo Fisher Scientific Inc.). Band intensity of western blots was obtained by Image Lab Software (Bio-Rad, Hercules, CA, USA) and normalized to GADPH.

Statistics analysis. Data are presented as mean \pm SD. Statistical significance of differences was assessed by one way ANOVA or Independent-Samples t-test using SPSS 16.0 software. A P-value of $<0.05$ was considered to indicate a statistically significant difference. Data for RT-qPCR were analyzed by $\Delta \Delta \mathrm{Cq}$ method (39).

\section{Results}

EESP suppresses the cell growth of HCT-8 cells. We examined the cell survival rate of HCT- 8 cells following EESP treatment using MTT assay. Cell viability decreased significantly by $82.46-18.31 \%$ following $0.5-1.5 \mathrm{mg} / \mathrm{ml}$ of EESP treatment 
A

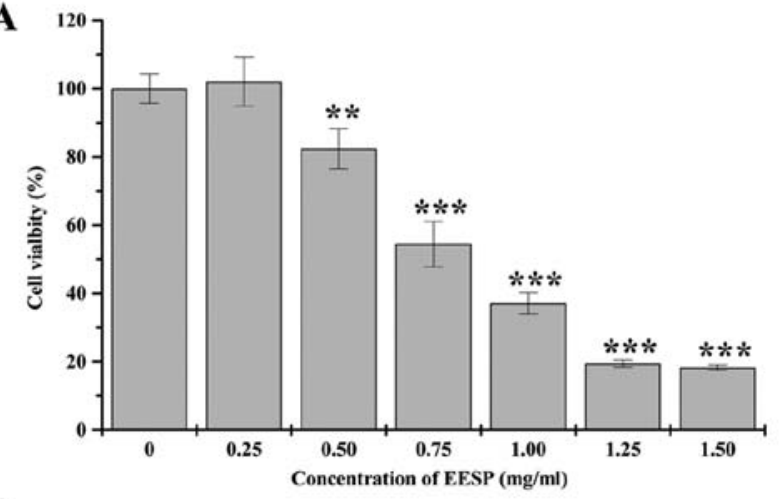

C

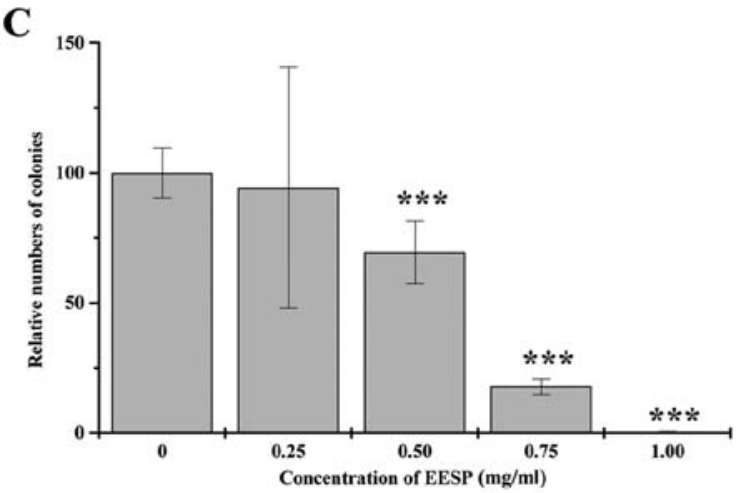

B

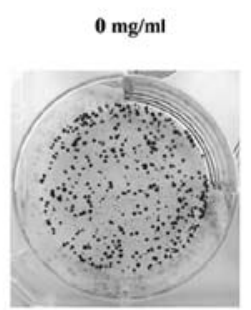

$0.25 \mathrm{mg} / \mathrm{ml}$

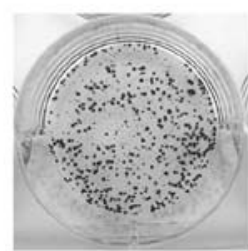

$0.50 \mathrm{mg} / \mathrm{ml}$

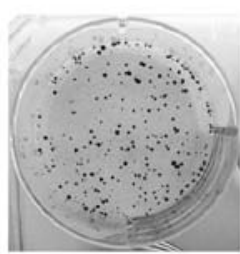

$0.75 \mathrm{mg} / \mathrm{ml}$

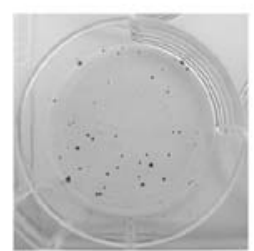

$1.00 \mathrm{mg} / \mathrm{ml}$

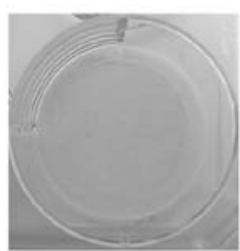

Figure 1. EESP suppresses the cell growth of HCT- 8 cells in $48 \mathrm{~h}$. HCT- 8 cells were treated following different concentrations $(0.25,0.50,0.75,1.00,1.25$ and $1.50 \mathrm{mg} / \mathrm{ml}$ ) of EESP for $48 \mathrm{~h}$. (A) Cell viability was determined by MTT assay. (B) Colony formation were determined after HCT- 8 cells treated following different concentrations $(0.25,0.50,0.75$ and $1.00 \mathrm{mg} / \mathrm{ml})$ of EESP for $48 \mathrm{~h}$. (C) Statistical analysis data from (B). Data are presented as mean \pm SD (n=3). ${ }^{*} \mathrm{P}<0.05,{ }^{* *} \mathrm{P}<0.01,{ }^{* * *} \mathrm{P}<0.001$.

A
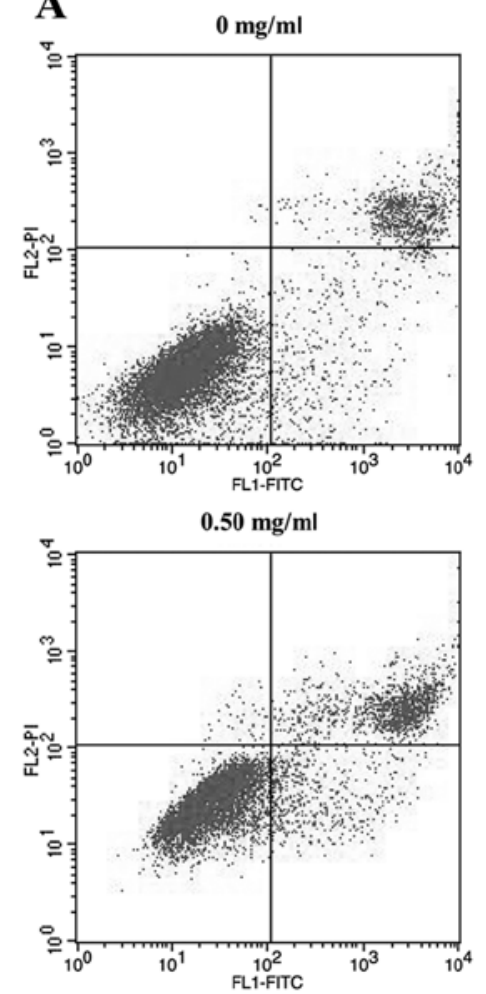

$0.25 \mathrm{mg} / \mathrm{ml}$
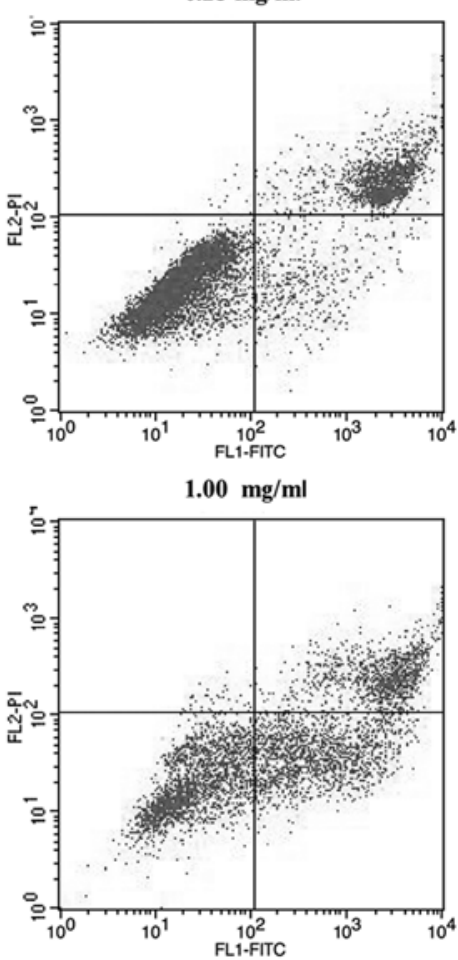

B

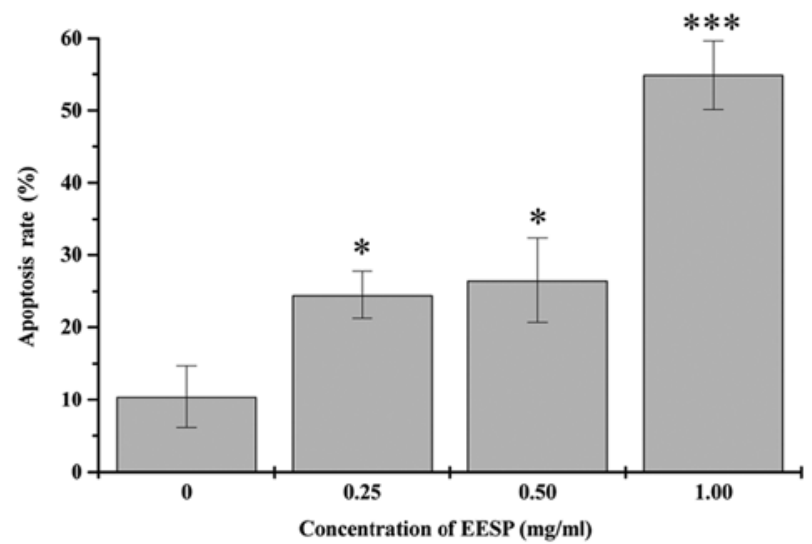

Figure 2. EESP induces apoptosis of HCT-8 cells. (A) HCT-8 cells were treated following different concentrations ( $0,0.25,0.50$ and 1.00 mg/ml) of EESP for $48 \mathrm{~h}$. After stained with Annexin V/PI, cells were analyzed by FACS. (B) Data from (A) is statistical analyzed. Data are presented as mean \pm SD ( $=3$ ). ${ }^{*}<0.05$, ${ }^{* *} \mathrm{P}<0.01,{ }^{* * * *} \mathrm{P}<0.001$.

for $48 \mathrm{~h}$, compared to untreated control cells. Based on these data, we calculated the $\mathrm{IC}_{50}$ value of EESP to be $0.77 \mathrm{mg} / \mathrm{ml}$ (Fig. 1A). In addition, we performed colony formation assays to determine the cell proliferation of HCT- 8 cells following EESP treatment. There was a dose-dependent reduction in the number of cell colonies by 94.34-0.43\% following EESP 
A

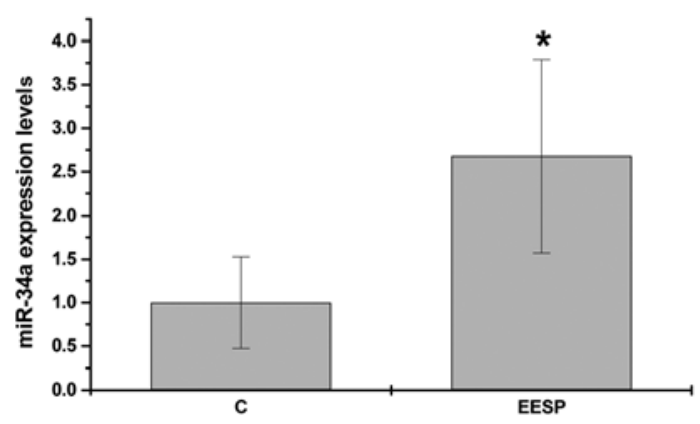

C

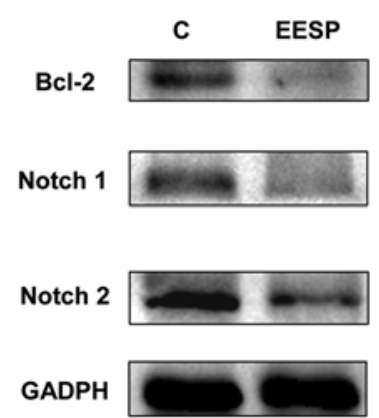

B

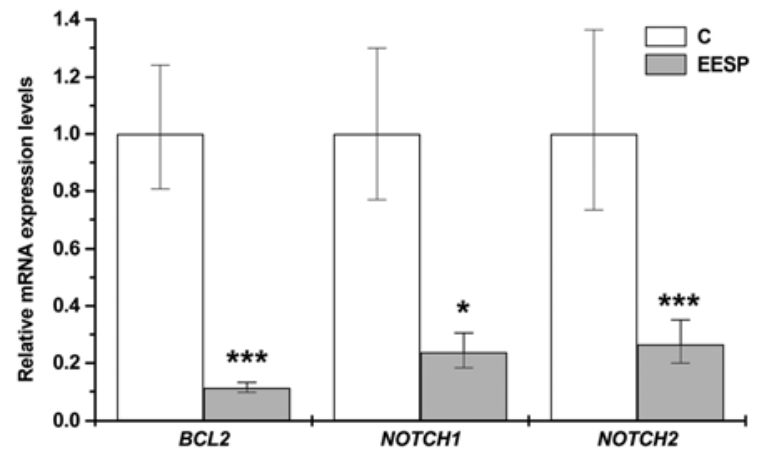

D

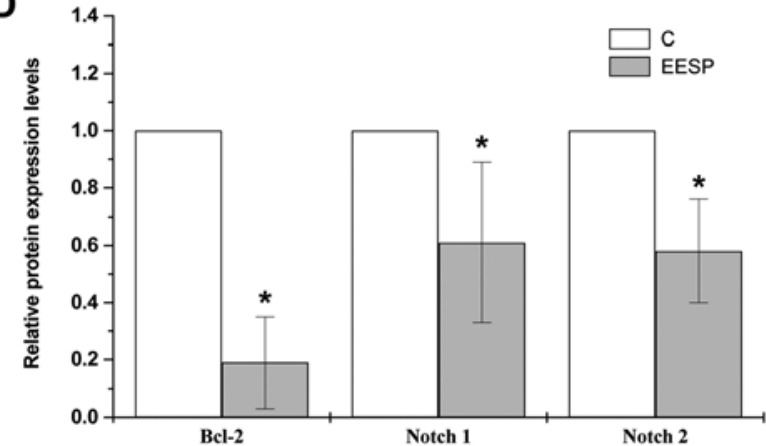

Figure 3. EESP upregulates endogenous miR-34a expression while downregulating its target genes in HCT- 8 cells. Following the treatment for IC ${ }_{50}$ value of EESP for $48 \mathrm{~h}$, total RNA and proteins of HCT-8 cells were extracted for real-time PCR and western blotting. (A) Relative expression level of miR-34a was confirmed and normalized to U6 RNA. (B) Relative mRNA expression levels of target genes of miR-34a were determined and normalized to $\beta 2$-MG (control). Data is presented as mean $\pm \mathrm{SD}(\mathrm{n}=3)$. ${ }^{*} \mathrm{P}<0.05,{ }^{* *} \mathrm{P}<0.01,{ }^{* * *} \mathrm{P}<0.001$. (C) Protein levels of Bcl-2, Notch1 and Notch2 were detected. (D) Relative protein levels of $(\mathrm{C})$ were determined and normalized to GADPH (control).

treatment, compared to untreated control cells (Fig. 1B and C). These results demonstrated that EESP suppressed HCT-8 cell growth in a dose-dependent manner.

EESP induces apoptosis of HCT- 8 cells. We determined whether the suppression of HCT- 8 cell growth following EESP treatment was due to apoptosis. There was a significant dose-dependent increase in the percentage of apoptosis which consisted of early and late apoptotic in HCT-8 cells (Fig. 2A and B). This indicated that EESP could induce apoptosis of HCT-8 cells.

EESP upregulates endogenous miR-34a expression while downregulating its target genes in HCT-8 cells. Previous studies have found that miR-34a can promote cell apoptosis by regulating Bcl-2, Notch1 and Notch2 (33-35). Therefore, we wished to determine the potential role of miR-34a pathway in Spica Prunellae, due to the ability of EESP to induce HCT-8 cell apoptosis as demonstrated above. There was a significant upregulation in miR-34a expression following treatment of EESP at $\mathrm{IC}_{50}$ for $48 \mathrm{~h}$, whereas the relative mRNA expression levels and protein levels of its target genes (Bcl-2, Notch1 and Notch2) were significantly downregulated (Fig. 3A-D).

EESP can rescue miR-34a-induced downregulation of Bcl-2, Notch1 and Notch2 expression. In order to verify that the effect of EESP was via activation of miR-34a pathway, we transfected miR-34a inhibitors into HCT-8 cells following EESP treatment to observe its antagonistic effects. With transfection of miR-34a inhibitors, the level of endogenous miR-34a was significantly decreased whereas its target genes Bcl-2, Notch1 and Notch2 were all increased significantly (Fig. 4A-D). In contrast, following EESP treatment, transfection of miR-34a inhibitors resulted in a significant downregulation of miR-34a target genes (Bcl-2, Notch1 and Notch2), which was consistent with our previous results (Fig. 3A-D). These results indicated that EESP can antagonize the effect of miR-34a inhibitors by increasing endogenous miR-34a expression. Furthermore, its regulation of miR-34a was most likely by targeting multiple oncogenes. Taken together, we revealed that EESP can rescue miR-34a-induced downregulation of Bcl-2, Notch1 and Notch2 expression.

\section{Discussion}

Conventional cancer chemotherapy is presented with various shortcomings, including increased drug resistance and adverse effects. Therefore, the use of natural products for treatment has received increased interest due to the potential for fewer side-effects. Currently, the use of TCM is the most common form of natural treatment, often used clinically for cancer therapy $(40,41)$. Spica Prunellae is a well-known ingredient in TCM which is used for the clinical treatment of many cancers $(42,43)$. Previous research into the anticancer mechanisms of Spica Prunellae was mainly focused on it protein expression, and currently very little is known on the basis of its miRNA expression. Our present study focuses on the miRNA expression of Spica Prunellae, and provides 
A

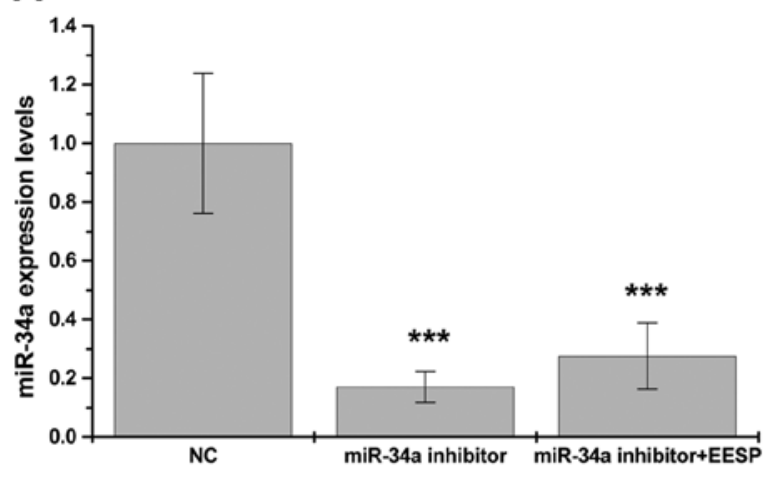

C
B

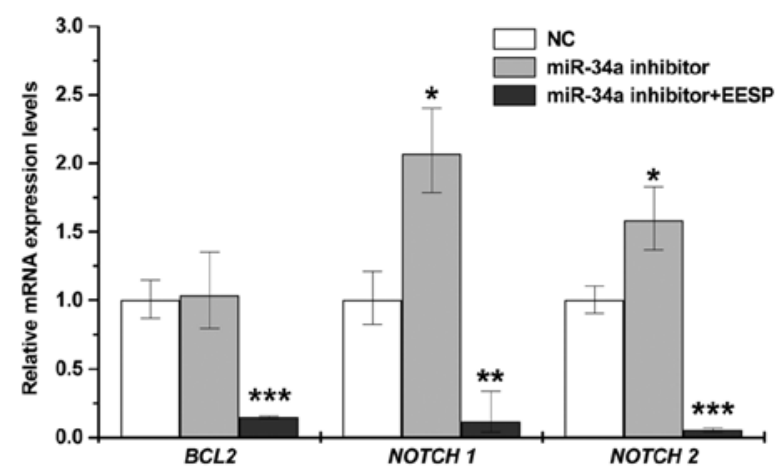

D

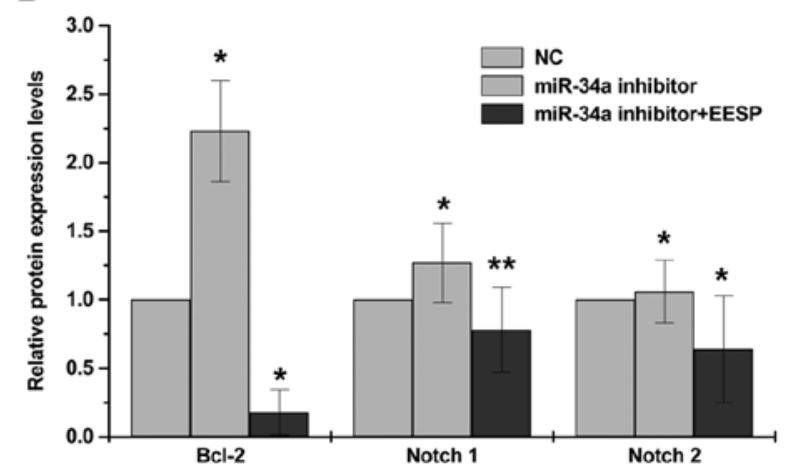

Figure 4. EESP can rescue miR-34a-induced downregulation of Bcl-2, Notch1 and Notch2. miR-34a inhibitor or its negative control were transfected into HCT- 8 cells for $24 \mathrm{~h}$. Then, culture media were replaced by $\mathrm{IC}_{50}$ value of EESP for $48 \mathrm{~h}$. With the harvest of cells, total RNA and proteins were extracted. Relative expression level of miR-34a (A) and its target genes (B) were confirmed and normalized to U6 (miR-34a) or $\beta 2$-MG (targets). Data are presented as mean \pm SD. ${ }^{*} \mathrm{P}<0.05,{ }^{* *} \mathrm{P}<0.01,{ }^{* * * *} \mathrm{P}<0.001$. (C) Protein levels of Bcl-2, Notch1 and Notch2 were detected by western blotting and (D) normalized to GAPDH (control). Data are presented as mean \pm SD. ${ }^{*} \mathrm{P}<0.05,{ }^{* *} \mathrm{P}<0.01,{ }^{* * *} \mathrm{P}<0.001$.

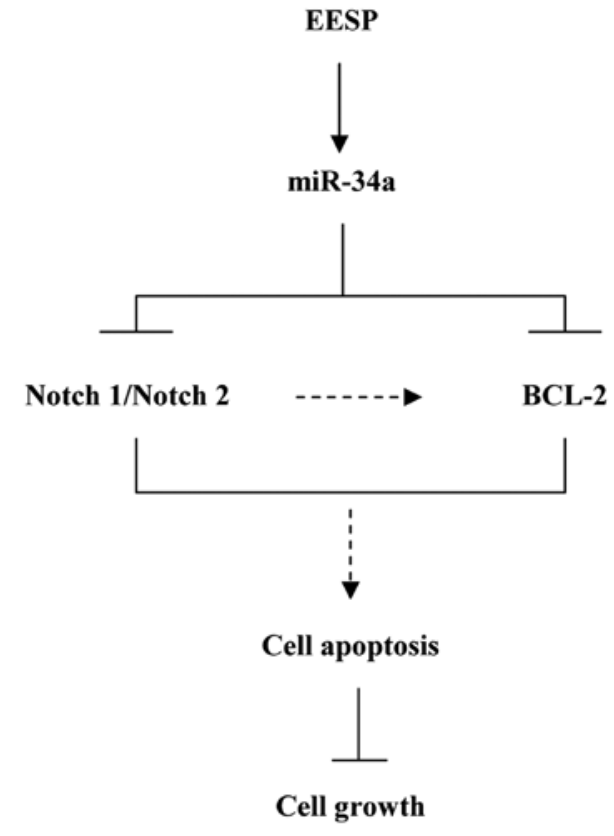

Figure 5. Suggested pathway of EESP1 action: suppresses the growth of human colon carcinoma cells by targeting multiple oncogenes via activating miR-34a.

crucial insight into the function and involvement of miRNAs for its tumoricidal activity.
miR-34a is a member of the miR-34 family, which can suppress tumor growth and metastasis by repressing cell cycle, epithelial-to-mesenchymal transition (EMT) and metastasis, while promoting apoptosis and senescence (44). In our study, EESP inhibited growth of human colon carcinoma HCT-8 cells and induced cell apoptosis. With miR-34a upregulation, its target genes Notch1, Notch2 and Bcl-2 were repressed following EESP treatment. Since these target genes were oncogenes and had apoptosis-targeting therapeutic potential in cancers (45-47), the results suggested that EESP might suppress growth of human colon carcinoma cells through promoting cell apoptosis by targeting Notch1, Notch2 and Bcl-2 via activating miR-34a (Fig. 5). Moreover, if miR-34a was the only downstream target for EESP, with miR-34a suppression by its inhibitor, the anticancer effect of EESP should be weakened or even disappeared in theory. However, compared with levels of cells transfected with miR-34a inhibitor only, the expression levels of Notch1, Notch2 and Bcl-2 were all downregulated significantly following the treatment of EESP with miR-34a inhibitor (Fig. 4). With these results, we believed that EESP could suppress expression of Notch1, Notch2 and Bcl-2 not only via miR-34a. In addition, previous work indicates that miR-34a suppressed tumors by the induction of cell apoptosis or cell cycle arrest (48). The process was mediated by the inhibitory effects of miR-34a on CDK4, CDK6, E2F3, cyclin D1, cyclin E2, c-MET, c-MYC and SIRT1 (48-50). We believed that the inhibition of cancer cells growth by miR-34a following EESP treatment must 
be achieved via targeting of multiple oncogenes besides the targets we studied above. As it consists of various compounds, EESP is involved in multiple pathways and targeted in various genes (51). Our results provide the possibility that EESP also suppress tumors or cancer cells through other pathways. The addition pathways await further investigation.

Notch signaling pathway is important for various developmental processes controlling cell fate decisions $(52,53)$. It is triggered through the binding of a ligand like Jagged/Delta/ Delta-like/Serrate on the membrane of one cell to a receptor such as Notch1/Notch2/Notch3/Notch4 on the membrane of the contacting cell (54). After activation, the cleaved Notch would release the cytoplasmic tail of NOTCH (NICD). With NICD translocated into the nucleus, it would associate with transcriptional factors and then regulate its target genes and modulate cell fate (55). In Notch pathway, some targets of miR-34a including Notch ligands such as Delta-likel (Dll1), Jagged1 (JAG1) and transcription factor hairy and enhancer of split-1 (HES1) (56-58) were reported, it does not rule out the possibility that they also take part in the mechanism as targets of miR-34a following EESP treatment. It is noteworty that Notch1 and Notch2 were found to induce apoptosis through Bcl-2 (59,60), with the fact that Notch1, Notch2 and Bcl-2 were downregulated following EESP treatment, we speculated that the repression of Bcl-2 following EESP treatment may be a consequence of regulation of both miR-34a and Notch1/Notch2 (Fig. 5). Future studies should address this hypothesis.

In summary, our study revealed that EESP suppresses the growth of HCT- 8 cells by targeting multiple oncogenes via activation of miR-34a pathway. It helps us to understand the effect for the anticancer activity of EESP better. We propose that the regulation of miR-34a is the likely mechanism for the anticancer activity of Spica Prunellae, although whether it can also induce cell apoptosis by directly regulating the expression of miR-34a target genes still requires further investigation.

\section{Acknowledgements}

We thank Jin Lin for help with the colony formation experiment. We appreciate Yiyi Jin for help with western blot experiment. Project 81603413 supported by National Natural Science Foundation of China, Natural Science Foundation of Fujian province of China (grant no. 2014J01360) and the Research Fund of the Education bureau of Fujian Province (grant no. JAT160244).

\section{References}

1. Siegel R, Naishadham D and Jemal A: Cancer statistics, 2013. CA Cancer J Clin 63: 11-30, 2013.

2. Chen W, Zheng R, Baade PD, Zhang S, Zeng H, Bray F, Jemal A, Yu XQ and He J: Cancer statistics in China, 2015. CA Cancer J Clin 66: 115-132, 2016.

3. Stein A, Atanackovic D and Bokemeyer C: Current standards and new trends in the primary treatment of colorectal cancer. Eur J Cancer 47 (Suppl 3): S312-S314, 2011.

4. Yoo BH, Lee BH, Kim JS, Kim NJ, Kim SH and Ryu KW: Effects of Shikunshito-Kamiho on fecal enzymes and formation of aberrant crypt foci induced by 1,2-dimethylhydrazine. Biol Pharm Bull 24: 638-642, 2001.

5. Lee MK, Ahn YM, Lee KR, Jung JH, Jung O-S and Hong J: Development of a validated liquid chromatographic method for the quality control of Prunellae Spica: Determination of triterpenic acids. Anal Chim Acta 633: 271-277, 2009.
6. Psotová J, Kolár M, Soušek J, Švagera Z, Vičar J and Ulrichová J: Biological activities of Prunella vulgaris extract. Phytother Res 17: 1082-1087, 2003.

7. Cheung H-Y and Zhang Q-F: Enhanced analysis of triterpenes, flavonoids and phenolic compounds in Prunella vulgaris L. by capillary zone electrophoresis with the addition of running buffer modifiers. J Chromatogr A 1213: 231-238, 2008.

8. Gu X, Li Y, Mu J and Zhang Y: Chemical constituents of Prunella vulgaris. J Environ Sci (China) 25 (Suppl 1): S161-S163, 2013.

9. Feng L, Au-Yeung W, Xu Y-H, Wang S-S, Zhu Q and Xiang P: Oleanolic acid from Prunella vulgaris L. induces SPC-A-1 cell line apoptosis via regulation of $\mathrm{Bax}, \mathrm{Bad}$ and $\mathrm{Bcl}-2$ expression. Asian Pac J Cancer Prev 12: 403-408, 2011.

10. Chu R, Zhao X, Griffin C, Staub RE, Shoemaker M, Climent J, Leitman D, Cohen I, Shtivelman E and Fong S: Selective concomitant inhibition of mTORC1 and mTORC2 activity in estrogen receptor negative breast cancer cells by BN107 and oleanolic acid. Int J Cancer 127: 1209-1219, 2010.

11. Yan SL, Huang CY, Wu ST and Yin MC: Oleanolic acid and ursolic acid induce apoptosis in four human liver cancer cell lines. Toxicol In Vitro 24: 842-848, 2010.

12. Nelson AT, Camelio AM, Claussen KR, Cho J, Tremmel L, DiGiovanni J and Siegel D: Synthesis of oxygenated oleanolic and ursolic acid derivatives with anti-inflammatory properties. Bioorg Med Chem Lett 25: 4342-4346, 2015.

13. Ryu SY, Oak M-H, Yoon S-K, Cho DI, Yoo GS, Kim TS and Kim KM: Anti-allergic and anti-inflammatory triterpenes from the herb of Prunella vulgaris. Planta Med 66: 358-360, 2000.

14. Popov AM, Osipov AN, Korepanova EA, Krivoshapko ON and Artiukov AA: Study of antioxidant and membrane activity of rosmarinic acid using different model systems. Biofizika 58: 775-785, 2013 (In Russian).

15. Basappa Maheswarappa N, Subbaiah V, Muthupalani M, Yamagani PK,Mohan K, Keshapaga UR, Vaikkathukattil AsokanS and Kalappurakkal RC: Antioxidant activity of carnosic acid and rosmarinic acid in raw and cooked ground chicken patties. J Sci Food Agric 94: 273-279, 2014.

16. Fallarini S, Miglio G, Paoletti T, Minassi A, Amoruso A, Bardelli C, Brunelleschi S and Lombardi G: Clovamide and rosmarinic acid induce neuroprotective effects in in vitro models of neuronal death. Br J Pharmacol 157: 1072-1084, 2009.

17. Khamse S, Sadr SS, Roghani M, Hasanzadeh G and Mohammadian M: Rosmarinic acid exerts a neuroprotective effect in the kainate rat model of temporal lobe epilepsy: Underlying mechanisms. Pharm Biol 53: 1818-1825, 2015.

18. Xu Y, Han S, Lei K, Chang X, Wang K, Li Z and Liu J: AntiWarburg effect of rosmarinic acid via miR-155 in colorectal carcinoma cells. Eur J Cancer Prev 25: 481-489, 2016.

19. Hao J, Ding XL, Yang X and Wu XZ: Prunella vulgaris polysaccharide inhibits growth and migration of breast carcinoma-associated fibroblasts by suppressing expression of basic fibroblast growth factor. Chin J Integr Med: Sep 1, 2016 (Epub ahead of print).

20. Sun H-X, Qin F and Pan Y-J: In vitro and in vivo immunosuppressive activity of Spica Prunellae ethanol extract on the immune responses in mice. J Ethnopharmacol 101: 31-36, 2005.

21. Lin W, Zheng L, Zhao J, Zhuang Q, Hong Z, Xu W, Chen Y, Sferra JT and Peng J: Anti-angiogenic effect of Spica Prunellae extract in vivo and in vitro. Afr J Pharm Pharmacol 5: 2647-2654, 2011. http://www.academicjournals.org/article/ article1380896211_Lin\%20et\%20a1\%20\%202.pdf.

22. Hwang SM, Lee Y J, Yoon JJ, Lee SM, Kim JS, Kang DG and Lee HS: Prunella vulgaris suppresses HG-induced vascular inflammation via Nrf2/HO-1/eNOS activation. Int J Mol Sci 13: 1258-1268, 2012

23. Collins NH, Lessey EC, DuSell CD, McDonnell DP, Fowler L, Palomino WA, Illera MJ, Yu X, Mo B, Houwing AM, et al: Characterization of antiestrogenic activity of the Chinese herb, Prunella vulgaris, using in vitro and in vivo (Mouse Xenograft) models. Biol Reprod 80: 375-383, 2009.

24. Feng L, Wang L, Ma YY, Li M and Zhao GQ: A potential in vitro and in vivo anti-HIV drug screening system for Chinese herbal medicines. Phytother Res 26: 899-907, 2012.

25. Oh C, Price J, Brindley MA, Widrlechner MP, Qu L, McCoy JA, Murphy P, Hauck C and Maury W: Inhibition of HIV-1 infection by aqueous extracts of Prunella vulgaris L. Virol J 8: 188, 2011.

26. Lin W, Zheng L, Zhuang Q, Zhao J, Cao Z, Zeng J, Lin S, Xu W and Peng J: Spica prunellae promotes cancer cell apoptosis, inhibits cell proliferation and tumor angiogenesis in a mouse model of colorectal cancer via suppression of stat3 pathway. BMC Complement Altern Med 13: 144, 2013. 
27. Zheng L, Chen Y, Lin W, Zhuang Q, Chen X, Xu W, Liu X, Peng J and Sferra TJ: Spica Prunellae extract promotes mitochondriondependent apoptosis in a human colon carcinoma cell line. Afr J Pharm Pharmacol 5: 327-335, 2011. http://www.academicjournals. org/article/article1380789242_Zheng\%20et\%20al.pdf.

28. Feng L, Jia X, Zhu M, Chen Y and Shi F: Chemoprevention by Prunella vulgaris L. extract of non-small cell lung cancer via promoting apoptosis and regulating the cell cycle. Asian Pac J Cancer Prev 11: 1355-1358, 2010.

29. Lin W, Zheng L, Zhuang Q, Shen A, Liu L, Chen Y, Sferra TJ and Peng J: Spica Prunellae extract inhibits the proliferation of human colon carcinoma cells via the regulation of the cell cycle. Oncol Lett 6: 1123-1127, 2013.

30. Kim S-H, Huang C-Y, Tsai C-Y, Lu S-Y, Chiu C-C and Fang K: The aqueous extract of Prunella vulgaris suppresses cell invasion and migration in human liver cancer cells by attenuating matrix metalloproteinases. Am J Chin Med 40: 643-656, 2012.

31. Iwakawa HO and Tomari Y: The functions of microRNAs: mRNA decay and translational repression. Trends Cell Biol 25 651-665, 2015

32. Ventura A and Jacks T: MicroRNAs and cancer: Short RNAs go a long way. Cell 136: 586-591, 2009.

33. Li L, Yuan L, Luo J, Gao J, Guo J and Xie X: MiR-34a inhibits proliferation and migration of breast cancer through downregulation of Bcl-2 and SIRT1. Clin Exp Med 13: 109-117, 2013.

34. Li Y, Guessous F, Zhang Y, Dipierro C, Kefas B, Johnson E, Marcinkiewicz L, Jiang J, Yang Y, Schmittgen TD, et al: MicroRNA-34a inhibits glioblastoma growth by targeting multiple oncogenes. Cancer Res 69: 7569-7576, 2009.

35. Pang RTK, Leung CON, Ye TM, Liu W, Chiu PC, Lam KK, Lee KF and Yeung WS: MicroRNA-34a suppresses invasion through downregulation of Notch1 and Jagged1 in cervical carcinoma and choriocarcinoma cells. Carcinogenesis 31: 1037-1044, 2010

36. Chen C, Ridzon DA, Broomer AJ, Zhou Z, Lee DH, Nguyen JT Barbisin M, Xu NL, Mahuvakar VR, Andersen MR, et al: Real-time quantification of microRNAs by stem-loop RT-PCR Nucleic Acids Res 33: e179, 2005.

37. Fang Y, Feng Y, Wu T, Srinivas S, Yang W, Fan J, Yang C and Wang S: Aflatoxin B1 negatively regulates Wnt/ $\beta$-catenin signaling pathway through activating miR-33a. PLoS One 8: e73004, 2013.

38. Yang W,Lian J,Feng Y, Srinivas $S$, Guo Z, Zhong H, Zhuang Z and Wang S: Genome-wide miRNA-profiling of aflatoxin B1-induced hepatic injury using deep sequencing. Toxicol Lett 226: 140-149, 2014.

39. Livak KJ and Schmittgen TD: Analysis of relative gene expression data using real-time quantitative PCR and the $2(-\Delta \Delta C(T))$ method. Methods 25: 402-408, 2001.

40. McPherson L, Cochrane S and Zhu X: Current usage of traditional Chinese medicine in the management of breast cancer: A practitioner's perspective. Integr Cancer Ther 15: 335-342, 2016.

41. Liao YH, Lin CC, Lai HC, Chiang JH, Lin JG and Li TC: Adjunctive traditional Chinese medicine therapy improves survival of liver cancer patients. Liver Int 35: 2595-2602, 2015.

42. Guo Q, Li J and Lin H: Effect and molecular mechanisms of traditional chinese medicine on regulating tumor immunosuppressive microenvironment. BioMed Res Int 2015: 261620, 2015.

43. Cao Z, Lin W, Huang Z, Chen X, Zhao J, Zheng L, Ye H, Liu Z, Liao L and Du J: Ethyl acetate extraction from a Chinese herbal formula, Jiedu Xiaozheng Yin, inhibits the proliferation of hepatocellular carcinoma cells via induction of G0/G1 phase arrest in vivo and in vitro. Int J Oncol 42: 202-210, 2013.
44. Vermeulen K, Berneman ZN and Van Bockstaele DR: Cell cycle and apoptosis. Cell Prolif 36: 165-175, 2003.

45. Duechler M, Shehata M, Schwarzmeier JD, Hoelbl A, Hilgarth M and Hubmann R: Induction of apoptosis by proteasome inhibitors in B-CLL cells is associated with downregulation of CD23 and inactivation of Notch2. Leukemia 19: 260-267, 2005.

46. Brzozowa-Zasada M, Piecuch A, Dittfeld A, Mielańczyk Ł, Michalski M, Wyrobiec G, Harabin-Słowińska M, Kurek J and Wojnicz R: Notch signalling pathway as an oncogenic factor involved in cancer development. Contemp Oncol (Pozn) 20: 267-272, 2016.

47. Gu Y, Masiero $\mathrm{M}$ and Banham $\mathrm{AH}$ : Notch signaling: Its roles and therapeutic potential in hematological malignancies. Oncotarget 7: 29804-29823, 2016.

48. Misso G, Di Martino MT, De Rosa G, Farooqi AA, Lombardi A, Campani V, Zarone MR, Gullà A, Tagliaferri P, Tassone $\mathrm{P}$, et al: Mir-34: A new weapon against cancer? Mol Ther Nucleic Acids 3: e194, 2014.

49. Sun F, Fu H, Liu Q, Tie Y, Zhu J, Xing R, Sun Z and Zheng X: Downregulation of CCND1 and CDK6 by miR-34a induces cell cycle arrest. FEBS Lett 582: 1564-1568, 2008.

50. Hermeking H: The miR-34 family in cancer and apoptosis. Cell Death Differ 17: 193-199, 2010.

51. Mao X, Wang G, Zhang W and Li S: A study on inhibitory effect of Spica prunellae extract on T lymphoma cell EL-4 tumour. Afr J Tradit Complement Altern Med 10: 318-324, 2013.

52. Artavanis-Tsakonas S, Rand MD and Lake RJ: Notch signaling: Cell fate control and signal integration in development. Science 284: 770-776, 1999.

53. Lai EC: Notch signaling: Control of cell communication and cell fate. Development 131: 965-973, 2004.

54. Sikandar SS, Pate KT, Anderson S, Dizon D, Edwards RA, Waterman ML and Lipkin SM: NOTCH signaling is required for formation and self-renewal of tumor-initiating cells and for repression of secretory cell differentiation in colon cancer. Cancer Res 70: 1469-1478, 2010.

55. Wang Z, Zhang Y, Banerjee S, Li Y and Sarkar FH: Notch-1 down-regulation by curcumin is associated with the inhibition of cell growth and the induction of apoptosis in pancreatic cancer cells. Cancer 106: 2503-2513, 2006.

56. Pang B, Pang Q, Pang H and Song G: Clinical effect of Jiutengzhuyu tablets on promoting blood circulation in women with oviducal obstruction. J Tradit Chin Med 32: 549-553, 2012.

57. de Antonellis P, Medaglia C, Cusanelli E, Andolfo I, Liguori L, De Vita G, Carotenuto M, Bello A, Formiggini F, Galeone A, et al: MiR-34a targeting of Notch ligand delta-like 1 impairs $\mathrm{CD} 15^{+} / \mathrm{CD} 133^{+}$tumor-propagating cells and supports neural differentiation in medulloblastoma. PLoS One 6: e24584, 2011.

58. Sun F, Wan M, Xu X, Gao B, Zhou Y, Sun J, Cheng L, Klein OD, Zhou X and Zheng L: Crosstalk between miR-34a and Notch Signaling Promotes Differentiation in Apical Papilla Stem Cells (SCAPs). J Dent Res 93: 589-595, 2014.

59. Ye QF, Zhang YC, Peng XQ, Long Z, Ming YZ and He LY: Silencing Notch-1 induces apoptosis and increases the chemosensitivity of prostate cancer cells to docetaxel through Bcl-2 and Bax. Oncol Lett 3: 879-884, 2012.

60. Gao F, Yao M, Shi Y, Hao J, Ren Y, Liu Q, Wang X and Duan H: Notch pathway is involved in high glucose-induced apoptosis in podocytes via Bcl-2 and p53 pathways. J Cell Biochem 114: $1029-1038,2013$ 